\title{
Defining STEAM Approaches for Higher Education
}

Claudia E. Carter ${ }^{1 *}$, Heather Barnett ${ }^{2}$, Kathryn Burns ${ }^{1}$, Nathan Cohen ${ }^{2}$, Eva Durall 3,4, Daniel Lordick ${ }^{5}$, Frank Nack ${ }^{6}$, Andrew Newman ${ }^{7}$, Shaun Ussher ${ }^{8}$

\author{
${ }^{1}$ Birmingham City University, UNITED KINGDOM \\ ${ }^{2}$ University of the Arts London, UNITED KINGDOM \\ 3 Aalto University, FINLAND \\ ${ }^{4}$ University of Oulu, FINLAND \\ ${ }^{5}$ Technische Universität Dresden, GERMANY \\ ${ }^{6}$ University of Amsterdam, NETHERLANDS \\ 7 Ars Electronica, AUSTRIA \\ 8 Science Gallery Dublin, Trinity College Dublin, IRELAND
}

*Corresponding Author: claudia.carter@bcu.ac.uk

Citation: Carter, C. E., Barnett, H., Burns, K., Cohen, N., Durall, E., Lordick, D., Nack, F., Newman, A. and Ussher, S. (2021). Defining STEAM Approaches for Higher Education. European Journal of STEM Education, 6(1), 13. https://doi.org/10.20897/ ejsteme/11354

Published: November 18, 2021

\section{ABSTRACT}

In an increasingly complex interconnected world, STEAM practices have gained attention in Higher Education (HE). The integration of Sciences, Technology, Engineering and Mathematics pedagogies with those from the Arts takes many forms with myriad intentions, processes and outcomes. Common aspirations pertain to equipping students with interdisciplinary skills required for the jobs market, increasing intellectual curiosity and collaboratively developing creative, socially equitable responses to complex global challenges. The Erasmus+ project STE AM Innovation and Curriculum involves seven European partners who have been pioneering STEAM approaches and methods. Using workshops, discussions, hacking processes and reflective practice, this collaborative work is the first comprehensive attempt to systematically analyse and showcase European approaches to STEAM in HE. Project outputs relate to the three project phases and include defining STEAM and a Handbook on STEAM approaches (Phase 1), the development of new STEAM methods (Phase 2) and developing evaluation frameworks (Phase 3). The Handbook collects and codifies HE STEAM approaches and provides a working definition highlighting key elements of STEAM projects and processes as well as guidance and inspiration for those looking to develop and introduce STEAM approaches in their institution. This paper focuses on Phase 1 outcomes and insights to help foster STEAM thinking and to tackle issues around joint STEM/Arts standards, and concerns in the HE arena such as modes of intellectual investigation, curriculum planning and the case for inter- and transdisciplinarity.

Keywords: higher education, STEAM approaches, STEAM methods, European STEAM practice

\section{EMBEDDING STEAM IN HE}

To date STEAM (Science, Technology, Engineering, Arts and Mathematics) approaches and projects have gained traction for pre-school, primary and secondary education (e.g., Bertrand and Namukasa, 2020; Burnard et al., 2020; Timotheou and Ioannou, 2021). Surprisingly little specific focus has been given to Higher Education 
(HE) applications in terms of potential diversity in opportunities, as well as attention to challenges and barriers (e.g., Kim et al., 2018). While there is a wide range of individual, institutional and national STEAM projects and perspectives, through our research connections and in the literature consulted, we, alongside others (e.g., Mejias et al., 2021), noticed a sparse coordinated effort to understand the ambiguities and tensions within the STEAM umbrella term, and what a shared understanding of STEAM in a HE context might, or should, encompass. For example, what are essential STEAM qualities for tertiary education, research and collaborations? What range of curricular and extra-curricular approaches and methods already exist? How well prepared and engaged are HE staff to embrace STEAM and what kind of training is, or should be, available for administrators, academics and senior management staff? How could we (better) monitor and evaluate STEAM activities in HE?

STEAM INC, an ERASMUS+ supported three-year project (2019-1-UK01-KA203-062032) ${ }^{1}$, aims to address this gap. Its partners are universities and HE-related organisations across Europe that have pioneered or experimented with a range of STEAM approaches and developed specific STEAM methods for engaging and upskilling staff, students and external stakeholders. The drivers are the increasingly complex societal and environmental challenges as well as a necessity for transdisciplinary working. For the latter, recognising the diversity and power of embedding Arts in STEM subjects and for Arts-related subjects to foster closer alliances working with people grounded in the Natural and/or Social Sciences is key. An underlying assumption is that specialist and mono-disciplinary approaches are no longer sufficient for preparing students for the job market or for addressing the complexity of society's problems and needs (e.g., Anonymous, 2016; Segarra et al., 2018).

As a consequence, this may challenge existing identities of students, teachers and researchers in HE in relation to their 'home discipline', knowledge base and nurtured abilities. STEAM can open up and enable different spaces, skills and competencies to form; but this does not mean that artists have to become scientists and scientists need to become artists. It seems, however, a timely exercise to examine the following questions: 'What does a STEAM framework and/or university STEAM culture look like?' and 'How is it, or should it be, institutionalised in HE?'

This paper adopts a reflective practitioner approach to elicit the multiple interpretations, perspectives and nuances of university-level STEAM-working and projects. It details some of the learning and insights gained to date from engaging critically and with curiosity to identify common denominators and key principles that can become useful anchors for meaningful and effective future STEAM work in the HE sector. Rather than following a conventional paper structure of Literature Review, Methodology, Results and Discussion this article is a reflective narrative but includes all of the above elements. It draws on the STEAM INC project partners' experiences and perspectives as well as the wider literature as appropriate. The STEAM INC workplan is the basis for the methodology, to help structure the reflections and findings, focusing specifically on the first 18 months of the project.

Based on a thorough online search for 'STEAM+approaches+HE' material at the time of writing of the STEAM INC project proposal, this is the first comprehensive attempt to collect and codify European approaches to STEAM in Higher Education. As such, the work has been exploratory, is contestable and should not be considered conclusive or exhaustive. For this paper, we have identified work that shares similarities in aims, particularly work led by Laura Colucci-Gray as part of a project funded by the British Educational Research Association (BERA). This work critically discusses the multiple policy directions and cultural traditions of STEAM in educational practice highlighting the multi-layered experiences, limitations, possibilities and relational understandings of STEAM education (Colucci-Gray et al., 2017, 2019; Colucci-Gray, 2020). However, while very relevant to the tertiary education level, their work was conducted for the primary and secondary school educational context and largely UK-focused rather than capturing an explicit wider European/international and HE perspective.

Specifically, and in parts aligning with but also going beyond Calucci-Gray's work, this contribution aims to elicit and discuss some tensions and ambiguities as experienced in the early parts of the STEAM INC project which appear to be of wider and fundamental relevance yet are difficult to find in the current literature (a notable recent contribution is by Meijas et al., 2021). Published STEAM projects and programmes tend to focus more on the positive aspects and their promising contributions rather than discuss various (mis-)understandings and 'uncomfortable' parts of STEAM experiments and expansion. This seems an opportune time to start eliciting and examining ambiguities and potential/actual barriers to STEAM working as well as highlighting the need for radical openness and reflectivity to guide and progress STEAM applications and uses in HE.

1 The project is funded under Call 2019 Round 1 KA2 - Cooperation for innovation and the exchange of good practices, KA203 - Strategic Partnerships for higher education.

$2 / 16$

(C) 2021 by Author/s 
Table 1. The STEAM INC partner organisations and main contributors

\begin{tabular}{|c|c|}
\hline Organisation, Location & Main Contributors \\
\hline \multirow{6}{*}{$\begin{array}{l}\text { Birmingham City University (Lead Partner) } \\
\text { Birmingham England, UK }\end{array}$} & Laura Veart (Project Manager, STEAMhouse) \\
\hline & Tom Cahill-Jones (STEAMhouse) \\
\hline & Claudia Carter (School of Built Environment) \\
\hline & Kathryn Burns (School of Fashion and Textiles) \\
\hline & Annette Naudin (School of Media) \\
\hline & Charmaine Stint (Research, Innovation \& Enterprise) \\
\hline \multirow{3}{*}{$\begin{array}{l}\text { Central Saint Martins College, University of the } \\
\text { Arts London } \\
\text { London, England, UK }\end{array}$} & Nathan Cohen (Course Leader of MA Art and Science programme) \\
\hline & Heather Barnett (Pathway Leader on the MA Art and Science) \\
\hline & Adrian Holme (Lecturer - MA Art and Science) \\
\hline \multirow{2}{*}{$\begin{array}{l}\text { Science Gallery Dublin, Trinity College } \\
\text { Dublin, Ireland }\end{array}$} & Shaun Ussher (Learning and Engagement Researcher) \\
\hline & Mairéad Hurley (Education \& Learning Manager, Science Gallery Dublin) \\
\hline \multirow{3}{*}{$\begin{array}{l}\text { Aalto University } \\
\text { Helsinki, Finland }\end{array}$} & Eva Durall (Department of Media, School of Arts, Design and Architecture) \\
\hline & Jaana Brinck (Department of Art, School of Arts, Design and Architecture) \\
\hline & Teemu Leinonen (Department of Media, School of Arts, Design and Architecture) \\
\hline \multirow{3}{*}{$\begin{array}{l}\text { Amsterdam University } \\
\text { Amsterdam, The Netherlands }\end{array}$} & Frank Nack (Informatics Institute, Faculty of Sciences) \\
\hline & Natasa Brouwer-Zupancic (Faculty of Science) \\
\hline & $\begin{array}{l}\text { Jacobijn Sandberg (Faculty of Science; creator of Bachelor in Humans, Society and } \\
\text { Technology programme) }\end{array}$ \\
\hline \multirow{4}{*}{$\begin{array}{l}\text { Dresden Technical University } \\
\text { Dresden, Germany }\end{array}$} & Daniel Lordick (Institute of Geometry; Geometric Modelling and Visualization) \\
\hline & Henriette Greulich (Center for Interdisciplinary Learning and Teaching) \\
\hline & Robert Fischer (Chair of Industrial Design Engineering) \\
\hline & Lisa Katharina Nickolaus (Geometric Modelling and Visualization) \\
\hline \multirow{2}{*}{$\begin{array}{l}\text { Ars Electronica } \\
\text { Lin₹, Austria }\end{array}$} & Andrew Newman (Producer of European Projects for Digital Humanism) \\
\hline & Veronika Liebl (Managing Director, Festival Prix / Exhibitions) \\
\hline
\end{tabular}

Table 2. STEAM INC's work programme and main outputs

\begin{tabular}{|c|c|c|}
\hline Outputs & Goals & Co-ordinator \\
\hline $\begin{array}{l}\text { Handbook on HE STEAM } \\
\text { Approaches } \\
\text { STEAM working definition } \\
\text { Training workshops } \\
\text { Website }\end{array}$ & $\begin{array}{l}\text { Guide HE STEAM-based course and module design, and } \\
\text { extracurricular STEAM approaches and methods clarifying points of } \\
\text { intersection between the different interpretations and applications of } \\
\text { STEAM. } \\
\text { Training HE professionals in how to identify and communicate these } \\
\text { points of intersection. }\end{array}$ & $\begin{array}{l}\text { Birmingham City University } \\
\text { (BCU) }\end{array}$ \\
\hline $\begin{array}{l}\text { STEAM Tools } \\
\text { Training workshops }\end{array}$ & $\begin{array}{l}\text { Learning from across the partnership and own critical reflective } \\
\text { practice, develop 'new' STEAM methods for HE that reflect/embed } \\
\text { STEAM characteristics as signalled in the working definition. }\end{array}$ & Central Saint Martins (CSM) \\
\hline $\begin{array}{l}\text { STEAM Evaluation Process and } \\
\text { Guidance } \\
\text { Training workshops }\end{array}$ & $\begin{array}{l}\text { Develop evaluation frameworks for the project and wider applications } \\
\text { to help measure the impact of STEAM approaches and methods and } \\
\text { aid holistic and ethical STEAM applications. }\end{array}$ & $\begin{array}{l}\text { Science Gallery Dublin } \\
\text { (SGD) }\end{array}$ \\
\hline
\end{tabular}

\section{THE STEAM INC PROJECT}

The Erasmus+ project 'STEAM Innovation and Curriculum' (short STEAM INC) is a collaboration between seven European partner organisations who have been pioneering STEAM approaches and methods (Table 1). The project started in October 2019 and finishes in January 2023 (extended from August 2022 due to the impacts of the COVID-19 pandemic).

The project objectives and associated workplan (Table 2) are three-fold:

1. Identify points of intersection across current European HE STEAM approaches and develop a collaborative definition of HE STEAM.

2. Produce methodologies for the implementation of STEAM thinking in HE education, policy and engagement.

3. Create an evaluation framework for measuring the effectiveness of STEAM processes in HEIs and HE partner organisations.

At the time of writing this article, the project was roughly halfway, with the first objective completed, the second underway and the third in preparation. The STEAM INC Methodology includes project partner meetings, local workshops, short training events, multiplier events and conferences. Most meetings, workshops and other events have been held online due to the COVID-19 pandemic. The one exception is the first project partner meeting held in Amsterdam in December 2019. Specific tools have included templates for data collection, peer review, reflection, developing persona / user profiles, and 'hacking' (involving deconstruction, translation/selection, evolution and hybrid recombination stages). 


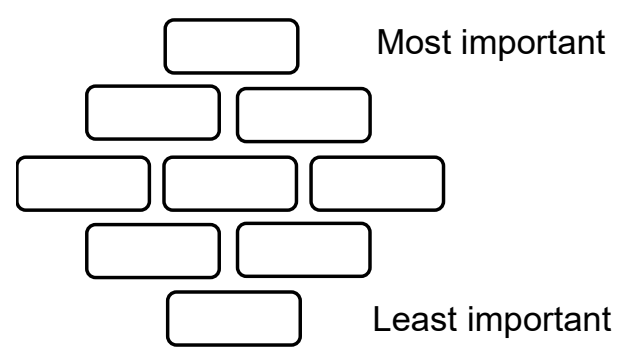

Figure 1. The Diamond Nine method

To address Objective 1 (the main focus of this paper) we identified commonalities and core elements across our different experiences, interpretations and applications of STEAM in Higher Education and HE-related ventures. The following paragraphs explain in some detail the methodology for developing a shared baseline of essential qualities for STEAM approaches in HE and how we arrived at our working definition and classification (structured into four stages). This section finishes with a brief outline of the Methodology for addressing the second and third objectives.

\section{Eliciting Points of Intersection across European HE STEAM Approaches}

\section{Stage 1: Creating a definition}

Before our first project meeting, each partner completed a template writing down individually or as a team their working definition of STEAM, detailing and reflecting on essential characteristics and outlining the specific context(s). It also probed into whether agreed definition(s) of STEAM existed at the institutional/organisational level. Partners presented their STEAM definitions at the first partner meeting. We progressed with collecting key words that were, in participants' opinions, representative of STEAM. Working in groups, we used the 'Diamond Nine' technique (Figure 1) to select, evaluate and collectively prioritise nine STEAM characteristics in a diamond shaped matrix. While not intended to be definitive, rather to promote discussion, several participants found the method prescriptive and 'forced'. This sparked useful debates and helped our understanding and appreciation of the plurality of STEAM perspectives, the diversity in ways of working and associated preferred collaborative/discursive methods and approaches.

Based on the outcomes of the Diamond Nine method, STEAM INC participants structured the key words to produce a definition that could encapsulate the broad, emerging collective understanding of what is encompassed by a STEAM approach. A major consideration was what kind of 'categories' fitted those attributes or competencies. Seven categories emerged which then helped to structure and synthesise the initial set of definitions from the group work into one working definition, through analysing and identifying the key and most common words used in those definitions. Finally, this resulted in a set of baseline attributes a STEAM practitioner or process might exhibit. The results of this Stage 1 work are presented in sections "HE-specific STEAM Context and Characteristics", "Ambiguities and Tensions" and "A Working Definition of STEAM for HE".

\section{Stage 2: Collecting and reviewing approaches}

Using the working definition established through stage 1, project partners then identified approaches from within their institutions that clearly expressed dimensions of STEAM. The selection of examples was flexible and included a broad range of applications across Higher Education, but with particular interest given to those examples relating to Higher Education courses \& curriculum development, internal and external engagement and policy. The approaches were then shared at an online international training event held in March 2020. The outcomes of this review process are presented in section "Generating a Typology of STEAM Approaches".

\section{Stage 3: Providing reflections}

Transdisciplinary experts from within the partnership were invited to consider what was distinctive and/or notable about the collected approaches based on their institutional perspective and personal experience (key points from those discussions are captured in section "Ambiguities and Tensions"). The raw opinions were grouped according to approach and theme, and insights across these distilled for inclusion in the HE STEAM Handbook (stage 4). 


\section{Stage 4: Producing practical guidance}

Having collected the approaches and identified themes, members of the partnership discussed and outlined the main practical considerations when developing and introducing STEAM approaches in Higher Education Institutions; also for inclusion in the Handbook.

The Handbook (Burns et al., 2021) is a 'stripped-down' publication featuring short overviews of a selection of the STEAM INC project partners' STEAM approaches, with more detailed information on specific approaches (and forthcoming methods under Objective/Phase 2) to be published on the project website (https://www.steaminnovation.org/resources). Importantly, the Handbook is written in plain English, avoiding (or explaining) jargon, and designed for ease of access to those in, or working with, HE institutions wishing to develop a STEAM curriculum, HE policy or wider engagement activities.

Sections "Creating New Methodologies" and "Creating Evaluation Frameworks" outline our method generation (the meta-method) to provide a clear overview of the entire project's aims and outputs. The full process, outputs and insights gained from work under the second and third objectives of the project will be reported in full in subsequent published outputs.

\section{Creating New Methodologies}

The second objective of the project involves developing new STEAM methods for implementation across the diverse $\mathrm{HE}$ contexts and considers their implications for HE policies. The focus is on developing a comprehensive methodological framework to support the integration of STEAM thinking in curriculum design through, for example, speculative design, art thinking, process-based research and participatory practice. The project partners' combined expertise in the field of inter- and trans-disciplinary education is well positioned to support investigations into developing the methods and processes to implement STEAM pedagogical approaches.

Through a process of deconstruction and the 'hacking' of existing methods, partners have generated a set of new STEAM methods, which have been tested in their individual contexts (universities and galleries/festivals). Once reviewed and evaluated, these methods will be compiled into an online educational resource, with consideration given to a range of potential users and possible applications. The intention is that methods created through the project will inspire and be adopted and adapted by diverse stakeholders across education, engagement and policy. The resulting methodologies and techniques will allow for creative appropriation and exploration of different points of view and, with the associated guidance, facilitate deeper enquiry and purposeful application.

\section{Creating Evaluation Frameworks}

Alongside the development of new methodologies is the creation of evaluation tools to assess the effectiveness of interdisciplinary cooperation across STEAM disciplines. These will facilitate eliciting the value of unconventional transdisciplinary approaches and methods arising from STEAM endeavours, to assess their efficacy and advance their potential expansion within curriculum design, engagement and policy. The project will use a STEAM process building upon the 'design science research process model' (Vaishnavi et al., 2019) to help identify problems, aid concept development, design and implement the evaluation frameworks within the project as well as making the methods available for wider use.

The process will address the following specific aspects:

- Evaluation of the new methods generated through the project and development of evaluation tools for wider dissemination and implementation.

- The development of a self-assessment tool which will allow students to better understand and position their STEAM competencies and to examine the benefits of participation in STEAM initiatives.

- A meta-level evaluation of the project as a whole to assess the partnership, the modes of collaboration and the resulting outcomes - utilising the STEAM definitions and competences generated within the project.

Collectively, the three objectives - the STEAM Handbook, New Methods and Evaluation Framework - aim to provide a comprehensive critical assessment of the current status and practice of STEAM within Higher Education as well as providing a practical tool kit which will enable and engender expansion of the field.

\section{DEFINING STEAM}

\section{STEAM Origin and Rationales}

STEAM arising from STEM has had multiple influences and contexts, including educational, political and economic agendas. One dominant argument has been that STEAM leads to innovation that in turn strengthens the economy (e.g., Catterrall, 2017; De Fay, 2005; Girão et al., 2018). Another key strand has been that STEAM 
approaches and methods make students more creative and empathetic (e.g., Catterrall, 2017; Guyotte et al., 2015). A third reason mentioned (especially for the US context) is to make STEM subjects more attractive and reverse the fall in Sciences and Engineering students (e.g., Billiar et al., 2014; Catterall, 2017; Drozd et al., 2017; Segarra et al., 2018). Furthermore, the emergence of the term STEAM in the USA in the 1990s initially seems to have been driven by funding being channelled towards STEM subjects and drastic cuts for the Arts; the relevance of Artsbased enquiry and methods for STEM-learning and research thus needed to be showcased (Catterall, 2017). It is, however, also important to note that STEAM initially developed outside formal curricula (Burnard et al., 2021), with MakerSpaces and similar endeavours. Several authors have commented on how using STEAM for economic or political gain, however, is problematic. This may be through 'mandating STEAM' but not actually training teachers and adequately resourcing schools, colleges and universities; or through exploiting the bandwagon and producing kits and resources under the label of STEAM that fall short of its key characteristics (Catterall, 2017).

It is noteworthy that not all relevant projects and programmes actually use the term 'STEAM' and many relevant approaches and methods may have no label or a different acronym. For example, since the 1960s, Frank Malina and son Roger F. Malina have worked on connecting Sciences and Engineering with the Arts, Design and the Humanities. This is illustrated in 'Leonardo' - the not-for-profit International Society of Arts, Science and Technology (ISAST) - and its publications as well as its sister organisation, L' Observatoire Leonardo des Arts et des Techno-Sciences, based in Paris. More recently, a series of White Papers were produced by authors belonging to the international Science, Engineering, Arts and Design Network to help convert ideas and a plurality of practices into concerted action (Malina et al., 2015). While led by American authors the scope of reach and contributions has been international (Thill et al., 2016). Furthermore, aligned with STEAM's focus on innovation and economic impact (not necessarily education), the European Commission launched the STARTS (or $\mathrm{S}+\mathrm{T}+\mathrm{ARTS}$ ) initiative to foster innovation at the nexus of Science, Technology and the Arts in 2015. Similarly, its predecessor/related programmes - ICT\&ART; FET-ART (e.g., supporting the FEAT project ${ }^{2}$ ); ICT\&ART Connect - have also focused on the inclusion of artists in innovation projects and non-artistic domains, such as Future and Emerging Technologies (FET) and Information and Communications Technologies (ICT). Their main aim has been to foster interdisciplinary encounters and create 'added value' and unexpected interesting results from such collaborations (Van Gansbeke and Groenewould, 2020, p5).

\section{General STEAM Characteristics}

The previous section helped explain the multiple interpretations of STEAM across countries and different contexts. In their work, Colucci-Gray et al. (2019) described STEAM as a "portmanteau term" (p1) which "draws together twisting points of definition, forming collections, configurations, and multiplicities of logic and practice" (p4). With STEAM gaining popularity, the variety of interpretations, programmes and projects is likely to grow further. Maybe this plurality is unavoidable, reflecting creativity and STEAM's driving forces. However, intentions, quality and the underlying paradigm(s) matter because they are likely to lead to different kinds of processes and outcomes. Therefore, defining this ground for collaboration is important in ensuring that participating in STEAM activities, be it in ways to enable and strengthen opportunities or supporting existing approaches and ventures, benefits individuals (e.g., to deepen and extend their knowledge, skills and competencies) and wider society.

Table 3 presents generic qualities of STEAM as highlighted in the literature, which include curiosity, creativity, critical thinking, cultural sensitivity, communication and collaboration. These show strong overlap with the ' 4 (and sometimes 5) Cs of $21^{\text {st }}$ century learning' (Partnership for $21^{\text {st }}$ Century Skills, 2007), namely Critical thinking, Collaboration, Creativity, Communication, and some add Confidence. Of these critical thinking and creativity seem to have attracted particular attention in the educational context (e.g., Bertrand and Namukasa, 2020; Chappell et al., 2019; Timotheou and Ioannou, 2021). STEAM INC discussions raised the question of 'How do we define critical thinking?' Is there a difference in its definition(s) between the Arts and STEM subjects? Artistic enquiries tend to start with considering the people, the context and the problem definition. In STEM those are less often questioned and explicitly examined; 'problem' definition is seen as given or 'apparent'. Also, does STEAM creativity in HE mean something different from STEAM in primary education, for example?

For example, the EU CREATIONS project, probing into creative pedagogical features within the primary and secondary education sector, identified eight characteristics: Balance and Navigation; Dialogue; Empowerment and Agency; Ethics and Trusteeship; Immersion and Play; Individual, Collaborative and Communal Activities for Change; Interdisciplinarity; Possibilities; and Risk (Chappell et al., 2019). These align closely with STEAM, with the exception that STEAM advocates inter-/transdisciplinarity and collaboration in all instances whereas creativity in STEM education could operate on an individual and mono-disciplinary basis as reflected in the CREATION project's definition of creativity in Science education (Chappell et al., 2019, pp 297-298):

${ }^{2}$ https://cordis.europa.eu/project/id/686527

$6 / 16$

(C) 2021 by Author/s 
Table 3. Overview of qualities associated with STEAM working and thinking

\begin{tabular}{|c|c|}
\hline Qualities / Characteristics & Sources \\
\hline Balance and Navigation & Chappell et al. (2019) \\
\hline Collaboration, Cooperation, Reciprocity & $\begin{array}{l}\text { Bertrand and Namukasa (2020); Chappell et al. (2019); Drozd et al. (2017); Guyotte } \\
\text { et al. (2014); Pollock et al. (2017); Segarra et al. (2018) }\end{array}$ \\
\hline Communication, Dialogue & Bequette and Bequette (2014); Chappell et al. (2019); Guyotte et al. (2014) \\
\hline $\begin{array}{l}\text { Connecting (people, knowledge, environment, } \\
\text { processes), Contextualisation, Bigger Picture }\end{array}$ & $\begin{array}{l}\text { Bequette and Bequette (2014); Burnard et al. (2021); Chappell et al. (2019); Clark and } \\
\text { Button (2011); Drozd et al. (2017); Guyotte et al. (2014) }\end{array}$ \\
\hline Creativity; Creative Thinking; Synthetic Thinking & $\begin{array}{l}\text { Bequette and Bequette (2014); Chappell et al. (2019); Conradty and Bogner (2018); } \\
\text { Guyotte et al. (2014) }\end{array}$ \\
\hline $\begin{array}{l}\text { Critical Thinking/Reasoning; Realising of Strengths } \\
\text { and Weaknesses }\end{array}$ & Bertrand and Namukasa (2020); Chappell et al. (2019); Guyotte et al. (2014) \\
\hline Cultural Sensitivity & de la Garza (2019); Segarra et al. (2018) \\
\hline Curiosity & Bequette and Bequette (2014); Bertrand and Namukasa (2020) \\
\hline Empowerment and Agency; Make/Do & Bertrand and Namukasa (2020); Chappell et al. (2019); Guyotte et al. (2014) \\
\hline Empathy & Guyotte et al. (2014) \\
\hline Ethics; Trust & Chappell et al. (2019); Guyotte et al. (2014) \\
\hline Experimentation and Failure; Iterations & Bequette and Bequette (2014); Bertrand and Namukasa (2020) \\
\hline Holistic & Drozd et al. (2017); Guyotte et al. (2014) \\
\hline Inclusivity & Bequette and Bequette (2014); Pollock et al. (2017); Segarra et al. (2018) \\
\hline Imagination & Bequette and Bequette (2014); Bertrand and Namukasa (2020); Chappell et al. (2019) \\
\hline Immersion and Play & Bertrand and Namukasa (2020); Chappell et al. (2019); Drozd et al. (2017) \\
\hline Innovation, Advancing knowledge/methods & Bertrand and Namukasa (2020); Kim et al. (2018) \\
\hline Interdisciplinary; Transdisciplinary & $\begin{array}{l}\text { Bertrand and Namukasa (2020); Chappell et al. (2019); Drozd et al. (2017); Guyotte } \\
\text { et al. (2014); Pollock et al. (2017) }\end{array}$ \\
\hline Meaning-making & Guyotte et al. (2014); Segarra et al. (2018) \\
\hline $\begin{array}{l}\text { Problem-based (problem-finding, -framing, - } \\
\text { solving); Authentic }\end{array}$ & $\begin{array}{l}\text { Bequette and Bequette (2014); Bertrand and Namukasa (2020); Clark and Button } \\
\text { (2011); Drozd et al. (2017); Guyotte et al. (2014); Kim et al. (2018); Segarra et al. } \\
\text { (2018) }\end{array}$ \\
\hline Process-orientated & $\begin{array}{l}\text { Bequette and Bequette (2014); Bertrand and Namukasa (2020); Chappell et al. } \\
\text { (2019); Guyotte et al. (2014) }\end{array}$ \\
\hline Project-based; Partnership & Drozd et al. (2017); Guyotte et al. (2014) \\
\hline Reflection & Bertrand and Namukasa (2020); Guyotte et al. (2014); Segarra et al. (2018) \\
\hline Risk-taking & Bequette and Bequette (2014); Chappell et al. (2019) \\
\hline Shared language; Common language & Guyotte et al. (2014); Van Gansbeke and Groenewould (2020) \\
\hline Tolerate ambiguity; Lack of specificity & Bequette and Bequette (2014) \\
\hline
\end{tabular}

"Purposive and imaginative activity generating outcomes that are original and valuable in relation to the learner. This occurs through critical reasoning using the available evidence to generate ideas, explanations and strategies as an individual or community, whilst acknowledging the role of risk and emotions in interdisciplinary contexts."

Creative pedagogies have shown to enhance pupils'/students' engagement and ingenuity (Chappell et al. 2019: 297). Conradty and Bogner (2018) in their paper unpacked the different meanings and implications of 'creativity', including that it opens the mind and leads to meaningful processes and ideas; allows sensitivity to problems and recognises gaps in knowledge; helps solve problems; facilitates fluid/associative thinking and the ability to change perspectives. Furthermore, they draw attention to two elements of creativity: Flow (explained as intuitive and a state of consciousness: being mentally immersed and feeling enjoyment and energised) and Act (explained as a cognitive process that can be taught/learnt and centres on deliberation).

A valid point of inquiry relates to whether STEAM qualities, and especially creativity, are (or should be) present in STEM. Why is there the perception that STEM subjects are non-creative (Chappell et al., 2019)? While a relevant and interesting question we have not focused on this element within the STEAM INC project. However, the presence of creative design processes across STEM and Arts disciplines were raised as an important case in point (and counter-argument to the above) which is also a point made by Bequette and Bequette (2014) and Guyotte et al. (2014). The following section focuses on the specific context and characteristics of STEAM in HE.

\section{HE-specific STEAM Context and Characteristics}

Most attention in the current STEAM-related literature seems to be about STEAM curricular and extracurricular practices and outcomes, as a specific aspect of creative and inter-/transdisciplinary pedagogies, methods and programmes. Fundamental aspects or the bigger picture (e.g., HE policies; public engagement) seem less covered. The STEAM INC partnership mix (Table 1) purposefully reflects a wide range of HE-relevant STEAM opportunities and diversity of STEAM initiatives championed by or including universities and other Higher Education bodies. Agreeing a working definition for STEAM in HE from STEAM INC participants' and partner 
institutions' perspectives provided a rich collection of viewpoints with ensuing critical debates as to what distinguishes STEAM from other creative or inter-/transdisciplinary approaches and which could be agreed to be the essential ingredients or characteristics.

Through the methods described in section "Eliciting Points of Intersection across European HE STEAM Approaches" we identified constituent elements or 'building blocks' seen as important for practical and meaningful applications and inspiration. STEAM approaches need the simultaneous use of a range of key ingredients and the structures, funding, skills etc. to provide a strong and lasting impact. Furthermore, the integration of STEAM qualities, capacities, and mindset is not only relevant between different people but also for each participant; i.e. being radically open to and actively engaged in learning and changing as part of STEAM ventures. Thus, STEAM 'connecting' and connectedness is more than forming relationships between disciplines, extending to all kinds of linkages between people/learners, environment(s) and philosophies to generate exciting new perspectives, methods and approaches of thinking and working. Relational acts (i.e. relating to and connecting) thus play a core role (Chappell et al., 2019; Berthoin Antal and Debucquet, 2019; Burnard et al., 2021).

In developing a working definition for STEAM in HE our emphasis was less on a finite definition but one that is sufficiently flexible and appealing to the wide range of involved disciplines and contexts. Furthermore, we looked for a definition that was distinctly 'STEAM' - as opposed to generally inter- or transdisciplinary. Hence, a central question and reminder for shaping the definition was to reflect: What characteristics made something STEAM? This discussion highlighted the importance of process (rather than outputs), and the specific characteristics relating to skills, competencies and mindset. Furthermore, what is the motivation for engaging with STEAM?

In the educational sector, there is usually a need for 'assessments' to measure the extent of learning outcomes achieved by students. In relation to HE engagement and policies there may also be the need to evaluate and demonstrate 'impact'. However, testing and assessing STEAM qualities such as critical thinking, creativity, holistic working as well as defining and measuring impacts of STEAM policies and events can be tricky. With regard to teaching and learning, different 'cultures' of assessments exist. For example, exam-based assessments are common for Mathematics and Natural Sciences whereas the Arts use more artefact, process and project-based assessments. STEAM INC participants regarded the former as tricky and the latter as more suitable for STEAM curricula. There will thus be scope to learn from Arts subjects how to assess fairly and meaningfully.

Furthermore, STEAM may require exploring different ways and new contexts for learning and conducting assessments (e.g., societal placements, community projects or industry/business collaborations). Immersion into the subject area and sense-making in STEAM projects are likely to go beyond cognitive and critical thinking abilities requiring the range of senses and emotional engagement by participants and learning through doing/making (Guyotte et al., 2014). Currently, HE STEAM often operates through extra-curricular knowledge-exchange (KE) and outreach activities, where outcomes and success may be measured in terms of 'new products' created or number of people involved (e.g., Birmingham City University's 'STEAMhouse'3). Since universities increasingly also have commercial wings, the question arises to what extent STEAM will sit in mainstream education (modules and courses) and/or be extra-curricular, research-focused or commercial?

It is clear, however, that whichever specific or multiple ways STEAM is being embedded in HE, it requires training the trainers to design and implement effective STEAM policies, projects, modules and courses. While some guides, White Papers, methods and policy reviews are available to 'teachers' (although largely US-based; e.g., Allina, 2018; Colucci-Gray et al., 2017; Drozd et al., 2017; Huser et al., 2020), there is so far little discussion and specific support available for academics at an institutional level or during their training. This needs attention, resources and some (fundamental) changes in organisational structures and administrative processes so that STEAM thinking and working are not just aspirations or isolated cases.

\section{Ambiguities and Tensions}

Ambiguities about STEAM start with its name: is it a collective and convenient abbreviation or a definitive list of disciplines/subject areas? Specifically, Science(s) as a stand-alone word tends to be interpreted as the 'Natural Sciences' rather than including 'Social Sciences'. Also, the Humanities, except for the Arts, are absent in the list yet STEAM examples in the literature and courses, projects and approaches by STEAM INC partners include subjects such as philosophy, history, human geography and politics. Overall, it seems that the term STEAM is used flexibly as to the composition of specific disciplines and subject areas involved but it is unclear whether to be STEAM a certain mix has to be ensured (e.g., a minimum of one Arts-related and one STEM-related discipline). Beyond bringing different disciplines and disciplinary knowledge together, STEAM INC participants also highlighted the importance of working at the boundaries or margins of the various disciplines. We discussed the need to reach beyond current academic knowledge and distinguishing STEAM from 'traditional' interdisciplinary

3 https:// steamhouse.org.uk/

$8 / 16$

(C) 2021 by Author/s 
working. In comparing our approaches, we found that artists can be characterised as 'catalysts', although artistic and creative elements should not be seen as only pertaining to the Arts.

In parallel, a core ambiguity is how the ' $\mathrm{A}$ ' is interpreted and integrated (e.g., what the 'Arts' component includes and whether it is central, equal or an add-on). While Design shares characteristics with STEAM aspects such as the emphasis on ideation and problem-solving strategies that support outside-the-box thinking (e.g., design thinking), how Design relates to the Arts is debatable; is it part of the Arts or a distinct separate field alongside Art? Rather than putting disciplines and people into boxes, and debating disciplinary definitions and boundaries, some STEAM INC participants proposed to use the term 'artistic qualities' and emphasised to look beyond simplistic conceptions of Art and Design (as common amongst 'non-artists'). This seems fitting as different perspectives co-exist, and STEAM seems at least partly about eliciting different perspectives.

For example, the S+T+ARTS Collaboration Toolkit published in 2020 aims to aid collaborative projects with artists and sees the Arts/Artist component as central. It is heavily artist-focused, innovation/technology driven and aiming to maximise outcomes (Van Gansbeke and Groenewould, 2020, p. 4). It conceives creativity as central and rooted in artistic practices and describes innovation as linked to imagination (and artists as particularly good at coming up with new concepts and ideas). Similarly, STEAM INC project discussions highlighted the role of Arts as a philosophical driver in terms of engendering modes of critical inquiry which are reflective and questioning (Danvers, 2003; Wang and Huang, 2018).

Many projects and academic articles are written from a STEM perspective where the Arts are introduced to STEM subjects (e.g., Chappell et al., 2019; Drozd et al., 2017; Segarra et al., 2018). While this may reflect specific contexts and needs, it is also a significant matter of the kind of mindset, preparations, objectives and methodologies adopted. In terms of the different knowledges accessed, sought or regarded as 'suitable evidence', natural sciences, for example, generally encourage explicit knowledge whereas the Arts often draw on tacit, embodied or haptic knowledge (Gardner, 1993; Barrett and Bolt, 2010, 2019; Robinson, 2011). Therefore, whether STEAM is approached from a predominantly Arts or predominantly STEM perspective may be significant. Guyotte et al. (2014) and Burnard et al. (2021) advocate a move away from Arts servicing STEM and the need to put both on an equal footing; a point also highlighted by Mejias et al. (2021). This should facilitate learning, experimenting and critical reflections by and between all participants. Furthermore, Burnard et al. (2021, p. 113) strongly argue for post-humanist transdisciplinary pedagogies and relational matters, for example reconciling "object-focused thinking" (abstraction; generally more typical of STEM subjects) with "contextually focused thinking" (more prominent in Arts and Design thinking and especially transdisciplinary endeavours).

Based on STEAM INC participants' experience, we observed that students and staff from Arts based faculties/courses more readily engage with STEAM opportunities than students and staff from STEM subject areas. Whether this relates largely to time constraints or is reflective of the cultural, institutional and disciplinary differences or mindsets (mental attitude) would be imprudent to assert (as we have not explicitly examined this). Still, there may be a greater readiness in artistic-focused individuals to experiment and be radically open to interand transdisciplinary research. Several STEAM INC participants (especially those from an Arts background working with students from STEM background) commented that some 'unlearning' is required alongside (social) learning to embrace STEAM working; for example, not jumping at usual paradigms and methods but being open to approach a topic from several different perspectives. Similarly, holistically framed education systems, such as found in Finland, may facilitate engagement with STEAM activities and thinking more readily.

Written from an Arts-based perspective, Van Gansbeke and Groenewould (2020, p. 9, 11) characterise the different influences of 'Art' on 'Technology' as: (i) questioning technology; (ii) inspiring technology and missiondriven projects; (iii) humanizing technology (e.g., inspiring prototyping); and (iv) influencing science by taking science out of the lab. They also emphasise the need to find a common language. The range of different artistic influences and importance of clarifying language (and concepts) were also highlighted in STEAM INC's phase 1 and kept recurring as important aspects of inter- and transdisciplinary working. Schnugg (2019, p. 37) highlights artists' role in terms of 'contextualisation' as follows:

"Contextualization can help to understand the questions scientific and technological work implies; it can point to both opportunities and downsides. These opportunities and downsides only become tangible when the newest research outcome is applied in real-life situations. Artists can ask these questions and invent scenarios - utopian, dystopian, and neutral ones—based on the information about scientific work and cutting-edge technologies. Thus, contextualization and implications of this work can be discussed before they become reality."

With regard to the role of A+STEM, STEAM INC partners commented that claims are made about STEAM working and thinking that are not necessarily measured or clearly evidenced. It is also unclear whether benefits of engaging with a STEAM project or module or other activity are short-lived or trigger lasting changes in 'agency', collaborations, sharing of power, and use of more holistic approaches. Some Arts-based STEAM INC participants 
saw STEAM as intricately bound into 'activism' and 'agency', especially with STEAM ventures linked to the complexity of current social-ecological changes and crises. However, some STEAM projects and endeavours are closely tied to business and industry and tend to be more product/output-driven; radical openness and activism would pose a challenge or risk. A relevant question that deserves further research and scrutiny is whether we overload the 'A' as part of STEM if we are expecting it to be disruptive (at least to some extent). This returns then to the argument of whether STEAM is conceived as applying A to STEM or (just as much) applying STEM to A. In any case, the 'A' should not mean 'Anything goes' but for STEAM to fully adopt the material and critical process base of the Arts that can be critiqued just as much as the data, information and processes deriving from STEM disciplines.

Stereotyping of disciplines may also be unhelpful. For example, STEAM INC participants shared experiences where in their own university-settings or in outside events/encounters the Arts were sometimes characterised as being more visual and context-based, whereas STEM subjects as being more text- and formula-based. These stereotypes are by no means unanimously supported; a point also evident in the literature (see e.g., Root-Bernstein, 2002; or Woodward, 1984). The role that is, or at least can be, played by aesthetics, imagery and other creative conceptions along with emotions and senses holds significance across the Natural and Social Sciences, Humanities, Engineering, Technology and Mathematics. For example, 'feeling' and 'knowing' could be seen as 'pairs' rather than different 'paradigms', as expressions such as 'knowing what one feels' and 'feeling what one knows' illustrate.

As apparent from some of the above discussions and context-setting, STEAM in the US and across Europe has a strong economic driver and industry/innovation link. While on the one hand enabling or supporting STEAM projects, they may also limit STEAM thinking and scope. For example, the expressed goal to make students fit for $21^{\text {st }}$ century employment is closely tied to environmentally unsustainable goals of national/global economic growth and monetary profit for some rather than enabling 'blue sky' and less product/output-tied opportunities for society and the planet. Another driver for embedding STEAM in (higher) education is the social-ecological complexity of our $21^{\text {st }}$ century world to enable more holistic and better development/solutions. Based on our literature search and sources consulted for this paper, no detailed investigation has been conducted on whether one of these drivers (and if so which) has dominated influencing STEAM endeavours and whether there may be a difference between 'red brick' (long established 'traditional' and research-focused) universities and those that are more vocational and employer-orientated ex-'polytechnics' (in the UK post-1992 'new' universities). All universities (in the UK at least) have become more neo-liberal and business-like, and university league tables employment-focused; both possibly fuel product-/goal-orientated STEAM approaches rather than more exploratory learning. This in turn may foreground STEAM projects with Art and Design influences focused on making/doing (e.g., Makerspaces), knowledge sharing and 'solutions', rather than 'new' knowledge, disruptive aesthetics and (design) activism (Gooding-Brown, 2000; Markussen, 2013). Although both can create positive outputs/outcomes for society, the latter is potentially revolutionary. In our project meeting discussions, we tentatively proposed that STEAM endeavours by nature should move beyond the academic/education context and relate to societal issues and/or challenges.

Most colleagues within the STEAM INC project had 'picked up' STEAM out of their own interest and through interdisciplinary degrees or transdisciplinary project experience. Does STEAM require the involvement of 'experts' or special training? Much of the current STEAM education literature focuses on how STEAM helps educate children and students; relatively less on training/supporting the teachers and what kind of level and mix of 'experts' this should involve. Chappell et al. (2019, p297), reporting on their earlier extensive CREATIONS project literature review, state that:

“(...) when delivered by skilled teachers, supported by effective training and sustainable, embedded pedagogical transformation transcending short-term partnership (Ben-Horin, 2015), STEAM pedagogies had the potential to be generative and exciting, enabling discussion and access to abstract scientific ideas, and facilitating understanding of pupils' thinking."

These findings clearly highlight the need for a long-term STEAM budget, professional STEAM training and sharing STEAM experiences. It is unclear, however, to what degree the direct involvement and learning from (external) experts is a necessity at the tertiary level. Thus, there is no clear picture as to the need for specific inquiry and knowledge from different parts of the STEAM delivering institution, their partners or stakeholders; and then how to use and mesh these.

Finally, Guyotte et al. (2014), amongst others, highlight conceptualising Art and Engineering (and STEM more generally) as social practices. This implies that universities (staff and students) will increasingly engage with external communities near and far. However, community engagement is often sporadic and via specifically targeted events rather than embedded into curricula or common HE practice. Even exhibitions of coursework or research projects are not always open to the public or external partners. STEAM has the opportunity to increase interactions with the public and societal affairs through changes in teaching spaces, assessments and designing new programmes 
and collaborative projects. This in turn will help practice-based learning, critical feedback and testing of ideas, improving cross-disciplinary and 'plain' language communication skills, increasing social-ecological awareness and sensibilities in students and staff.

\section{A Working Definition of STEAM for HE}

STEAM INC's aim was to be decisive in expressing a working definition for the HE context that is inclusive but not vague in its core make-up of 'principles'. Our initial collection of what partners classed key characteristics and fundamental aspects of their STEAM work and understandings were sorted into what emerged as seven categories: Competencies - Paradigms - Motivation - Qualities \& Characteristics - Process (methodologies etc.) - Mindset - Prerequisites. This then helped to structure and synthesise the initial set of definitions from the group work into one working definition, through analysing and identifying the key and most common words used (these are bolded in the bulleted definition below). Some terms featured under several categories (e.g., student-centred can be a paradigm but also a process). Out of these, critical thinking was the most frequently identified quality of a STEAM approach in Higher Education. However, critical thinking is not necessarily considered the core competency that in itself suffices. On the contrary, our discussions illustrated the importance of the combination of qualities and attention to the underlying paradigm(s) as key. By employing these characteristics together, STEAM creates a (mental, physical, creative) space that adds value, new perspectives and fresh thinking. Our agreed STEAM definition adopted the following format.

A Higher Education approach to STEAM (potentially) involves:

- a culture (or cultures) that puts the Arts and Sciences on an equal footing

- operating within a paradigm that is process-driven, student-centred, holistic and provides permission to fail alongside being comfortable with uncertain end-results

- being collaborative, diverse and delivered through safe spaces

- establishing a mindset of radical openness, flexibility, reflection, experimentation and curiosity

- generating qualities that promote learning, cooperation and multi-modality

- supporting practices that are transdisciplinary and emphasise prototyping and making whilst considering modes of assessment

- developing competencies of critical thinking, creativity and communication whilst investigating how these can be applied to generate solutions.

While not viewing this outcome as 'final', the partnership agreed that the working definition clearly signalled the set of baseline attributes a STEAM practitioner or process might exhibit.

\section{GENERATING A TYPOLOGY OF STEAM APPROACHES}

In light of the diversity of STEAM approaches in (higher) education contexts, devising some kind of classification may help distinguish between different modes of intellectual investigation, aid curriculum planning and support the case for (group-based) trans-/interdisciplinary working. STEAM INC collected and mapped different examples of STEAM approaches in a HE setting with the intention to identify themes that link the approaches, so that routes to embedding STEAM in HE can be more easily discerned and followed. After reviewing the STEAM INC partners' approaches as a group, it was agreed that four themes could be used to best describe the scope and nature of the information collected. These were Behaviour, Cultures, Engagement, and Spaces.

Behaviour here means the way that a person or group of people act, particularly in relation to collaboration. Cultures is about the collective values, beliefs and modes of operation which are advocated by STEAM practitioners. Engagement concerns the processes which promote open involvement and stimulate wide interest. Space denotes the places from which STEAM activity is delivered; this is traditionally a kind of shared studio or working space, but increasingly (and due to the COVID-19 pandemic) virtual spaces through digital technologies and facilitating software. Within and across these categories a huge breadth and variety in time scales, spatial scales, participatory scales, outputs/creations exist. The STEAM INC Handbook (Burns et al., 2021) illustrates the application of this typology and summarises the outcome of the work under Objective 1 (section "Eliciting Points of Intersection across European HE STEAM Approaches") and outlines what STEAM in HE means and comprises.

Finally, in terms of categorisation, discussions at the Amsterdam workshop led to drawing a distinction between a 'STEAM approach' and a 'STEAM method'. In general, the former can be considered the wider expression, covering strategies, programmes, fields, and philosophies, whereas the latter relates to specific techniques. Of 
course, examples exist and can be imagined where overlap occurs but the fundamental perspective in our view is that STEAM methods can be seen to sit within STEAM approaches.

\section{REFLECTIONS ON IMPLEMENTATION OPPORTUNITIES AND BARRIERS}

There appear to be two predominant routes to implementing STEAM approaches within HE curricula, influenced by the persisting structural and epistemic difficulties in the integration of STEAM disciplines (see e.g., Costantino, 2017; Mejias et al., 2021). Especially, the latecomer 'A' remains ineffectively integrated with STEM. This is borne out in the two perspectives, as discussed in section "Defining STEAM", of choosing between adding A to STEM or adding STEM to A. The first route (A to STEM) consists of embedding STEAM activities, methods, processes and exercises into existing STEM curricula. This necessitates cross-faculty exchange and coordination between STEM academics to introduce STEAM approaches that have predominantly been developed within the Arts. Alternatively, or additionally, this first route of introducing STEAM approaches to STEM students can be implemented through university-wide art programmes such as those undertaken at Aalto University, Finland (https://www.aalto.fi/en/uwas), or through the active promotion of extra-curricular engagement with STEAM.

The second route (STEM to A) sees the implementation of STEAM into HE curricula through the full development of STEAM-centric degree programmes. Current examples include the MA Art and Science at Central Saint Martins, University of the Arts London (https://www.arts.ac.uk/subjects/fine-art/postgraduate/ma-artand-science-csm) and the Bachelor of Creative Intelligence and Innovation at the University of Technology Sydney (https://www.uts.edu.au/future-students/transdisciplinary-innovation/undergraduate-courses/creative-

intelligence-and-innovation). This route focuses more on learning objectives that prioritise transdisciplinary thinking informed by art and design practices and encouraging a broad understanding of STEM, but not necessarily a deep knowledge of specific STEM disciplines.

Neither of these two existing routes is necessarily better. The establishment and running of STEAM courses and projects seem to rely on persistence by academics to experiment, gain support (amongst peers and the organisation's executives) and be creative in light of structural barriers, limited/no training, and limited resources (including lack of funding to retain STEAM-experienced staff and lack of support for longer-term programmes). Most university faculties and departments still have mono-disciplinary structures for running courses, funding and administration, with careers and research impact fast-tracked through specialisation rather than transdisciplinary working (e.g., Schuitema and Sintov, 2018). This then seems to have led to many relatively small scale and extracurricular STEAM activities rather than STEAM modules, courses and cross-faculty programmes. Many universities rely on external funding to develop STEAM expertise and collaborations. This not only brings financial uncertainty but also means that existing HE structures may be slow to adjust or transform to facilitate transdisciplinary STEAM working.

There is however, not just a structural barrier but also more deeply underlying issues relating to ontology and epistemology as expressed in different disciplines having different paradigms; and this creates barriers. Does STEAM need new paradigm(s) or is it sufficient to try and make connections between existing disciplinary paradigms? Since, STEAM tends to be modelled on transdisciplinary working (as opposed to multi-or interdisciplinary), radically open processes and meaningful longer-term STEAM collaborations across and beyond the HE sector are likely to mainstream novel ways of working and perceiving, framing and studying socialecological issues in their economic and political context. Such endeavours align closely with post-modern posthumanist transdisciplinary pedagogies. Still, with the plurality of STEAM approaches, would this create somewhat superficial STEAM identities and adapted ways of thinking but not necessarily achieve new relational ways of thinking and working? Thus, STEAM needs defining and underlying values and drivers made explicit for specific STEAM applications, advocating critical reflection on the different strands and sometimes opposing aspects, goals and approaches to STEAM.

\section{CONCLUSIONS}

The STEAM INC project reviewed personal, institutional, national and international perspectives to produce a shared understanding of what STEAM in Higher Education might encompass. Our work shows that embedding STEAM approaches and methods in HE will continue to be a worthwhile endeavour. Employers are increasingly seeking the combination of creative/design and technical/scientific capabilities (Cultural Learning Alliance, 2017) nurtured by STEAM. Likewise, societies will adopt STEAM processes to solve the bigger issues and reduce a dependence on economic oriented measures of achievement. Successful STEAM approaches do not shoehorn Arts - in its widest interpretation - into STEM as a catalyst for learning and innovation (e.g., Burnard et al., 2021). 
On the contrary, they carefully consider the process and intended outcomes as well as the mindset and attitudes of participants. The following subsections offer some conclusions on STEAM HE challenges, barriers and opportunities using the different relevant parts of our STEAM HE definition at the start.

\title{
STEAM Standards and Support
}

"generating qualities that promote learning, cooperation and multi-modality"

"flexibility, reflection, experimentation and curiosity"

STEAM has been described as a social practice and increasing ecological awareness (e.g., Guyotte et al., 2014). It has the potential to move from a marginal pursuit or 'add-on' to facilitating a fundamental shift in the way we explore, define and frame social-ecological challenges and the way we structure and deliver education. Inspiration, guidance and reference to STEAM principles, as expressed in our working definition, can provide a useful baseline to promote holistic perspectives and avoid narrow short-term 'bandwagon' activities in the HE context.

STEAM thinking and practice has changed over time. For example, we have seen an evolution from MakerSpaces (hands-on) to more discursive, reflective and philosophical 'labs'. Artificial and virtual reality technologies have pushed explorations and practices from 2D to 3D. The use of a wider range of techniques, including 'play' have become more accepted as effective and safe ways of experimentation and embracing 'failure' as an inherent part of the experimental process and a positive driver to innovation. While many STEAM activities are still extra-curricular or only occupy a very small space within the curriculum, research and attention to STEAM has been steadily increasing, in part evident in the volume of STEAM publications and STEAM education and research programmes.

The success and impact of STEAM learning, skills and competencies may not easily be captured with existing assessment and evaluation tools. This is therefore an area that the STEAM INC project is developing to facilitate demonstrating the value of STEAM approaches and methods. Indeed, STEAM cannot be expected to happen without effort. While it does not need to be high-cost or high-tech, it does require funding, expertise and institutional support. Increasing STEAM practices will require the training of teachers/STEAM-practitioners all the way from kindergarten to tertiary education, research and professional practice. This must include a recognition of the need for artistic curiosity and endeavours as empathetic and positive life skills to enable wider, more holistic, perspectives and meaningful (and benign) endeavours. Such training and support for STEAM requires dedicated funding and expertise with long-term programmes to avoid a brain-drain.

The focus on future and emerging technologies / the digital revolution, while on the surface exciting, may become a red herring and trap (as pressure over natural resources increase, environmental impacts escalate and negatively impact on societies - especially affecting those less well-off). Interestingly, some STEAM projects have explicitly focused on inclusion and reaching out to minorities, underrepresented or disadvantaged groups (e.g., Claville et al., 2019; Pollock et al., 2017) and international students (e.g., de la Garza, 2019).

\section{Drivers and Modes of Investigation}

\begin{abstract}
"a culture (or cultures) that puts the Arts and Sciences on an equal footing"
"establishing a mindset of radical openness"

"developing competencies of critical thinking, creativity and communication whilst investigating how these can be applied to generate solutions"

The diverse drivers of STEAM can cause some tensions. Putting the Arts and STEM subjects on an equal footing and not seeing either as subservient to the other has emerged as an important point in STEAM INC discussions. STEAM is a holistic venture, which challenges participants to engage cognitively, emotionally and imaginatively in diverse and new ways. The 'Flow' and 'Act' analogy (in the "General STEAM Characteristics" section) highlights the importance of connecting to our inner self, being intuitive and developing faculties from within rather than being brainwashed; being critical and creative in knowledge acquisition (rather than formal education driving out creativity and intuition). Creativity can help identify problems (open eyes) and solve problems (make a change).

Whatever mode of intellectual, experiential or emotional investigation, STEAM requires being radically open and reflective. In transdisciplinary working, attention to language is key; communicating in a way that is inclusive and accessible, open to discussion and being challenged, ready to explain and clarify. Desired outcomes and suitable processes may need negotiation and adaptation to suit specific endeavours and participants.
\end{abstract}

\section{Curriculum Planning (and Beyond)}

"operating within a paradigm that is process-driven, student-centred, holistic and provides permission to fail alongside being comfortable with uncertain end-results"

"being collaborative, diverse and delivered through safe spaces" 
Student-centred learning has become the aspirational norm, and is done in many different ways. While problem-centred and collaborative approaches are not new, how to design and facilitate these effectively is the decisive factor. Students need to feel safe to share progress, explore options, without fear of 'looking stupid' or failing in front of peers and tutors. Some STEAM scholars also emphasise the need to move from being problemcentred to being process-focused that allows exploratory, aesthetic and accidental elements (e.g., Pollock et al., 2017). This relates to the issue of opening up what the actual (underlying) problems are and can facilitate breaking out of technological and policy path 'lock-ins' to explore more promising and sustainable futures. Also, STEAM can open up a wider set of styles of learning (e.g., performing or visual Arts for Mathematics and Sciences) and knowledge sharing by both tutors and students. Authentic, real world tasks can lead to deeper understandings within and beyond assignment/project tasks. The STEAM INC Handbook provides some insights into the wide range of long, short, simple, complex approaches that have already been developed and tested in the European HE context.

\section{The Case for Transdisciplinarity}

"supporting practices that are transdisciplinary and emphasise prototyping and making whilst considering modes of assessment"

Transdisciplinary working includes a range of disciplines within and outside education settings, encompassing research, policy and practice perspectives to explore issues and address challenges. In STEAM, the Arts are sometimes used as a handmaiden to STEM, but is best involved in its own right as well as in rediscovering the Arts-based qualities in other disciplines or indigenous cultural thinking and learning (e.g., holistic rather than reductionist; critical rather than narrow theories; e.g., de la Garza, 2019). We have outlined and discussed enabling factors and tensions for transdisciplinary STEAM working and these need addressing through changes in HE policies, structures, administration and individuals' mindset. Including more practice and collaborative processbased learning and assessments such as advocated in 'flipped curriculum' activities are a good starting point. However, for STEAM to truly take roots and become embedded across the HE sector, faculty and course structures may have to open up to allow more pick and mix choices and more diverse assignments that reflect STEAM qualities as described in our working definition and foster STEAM competencies and skills as outlined in Table 3.

Lastly, in response to 'What is STEAM and what does it mean for HE?' we do not claim full consensus and our working definition is certainly open to being contested. However, we are sure that STEAM should be challenging and pull people out of their comfort zone.

\section{ACKNOWLEDGEMENTS}

This paper has been informed by the varied formal presentations, working sessions and informal discussions and exchanges that took place writing the project proposal and then delivering the project. A big thank you to all STEAM INC participants as listed in Table 1 and the following: Andre Nusselder, Jean O'Shea, Caroline Singh Belmar.

\section{REFERENCES}

Allina, B. (2018). The development of STEAM educational policy to promote student creativity and social empowerment. Arts Education Policy Review, 119(2), 77-87. https://doi.org/10.1080/10632913.2017.1296392

Anonymous (2016). STEM vs. STEAM: How the sciences and arts are coming together to drive innovation. The Independent, 26 May 2016. https://www.independent.co.uk/student/student-life/studies/stem-vs-steam-howsciences-and-arts-are-coming-together-drive-innovation-a 7047936.html

Barrett, E. and Bolt, B. (eds) (2019). Material Inventions: Applying Creative Arts Research. https://doi.org/10.5040/9780755603695

Barrett, E. and Bolt, B. (eds) (2010). Practice as Research: Approaches to Creative Arts Enquiry. London: Tauris.

Bequette, J. and Bequette, M. B. (2012). A place for art and design education in the STEM conversation. Art Education, 65(2), 40-47. https://doi.org/10.1080/00043125.2012.11519167

Berthoin Antal, A. and Debucquet, G. (2019). Artistic Interventions in Organizations as Intercultural Relational Spaces for Identity Development, in M. A. Peters and S. M. Weber (eds.), Organization and Newness: Discourses and Ecologies of Innovation in the Creative University (pp 149-166). Brill, Leiden. https://doi.org/10.1163/9789004394827_012

Bertrand, M. G. and Namukasa, I. K. (2020). STEAM education: student learning and transferable skills. Journal of Research in Innovative Teaching \& Learning, 13(1), 43-56. https:/ / doi.org/10.1108/JRIT-01-2020-0003 
Billiar, K., Hubelnamk, J., Oliva, T. and Camesano, T. (2014). Teaching STEM by Design. Advances in Engineering Education, 4(1), 1-21.

Burnard, P., Colucci-Gray, L. and Sinha, P. (2021). Transdisciplinarity: letting arts and science teach together. Curriculum Perspectives, 41 (April), 113-118. https:/ / doi.org/10.1007/s41297-020-00128-y

Burnard, P., Sinha, P., Steyn, C., Fenyvesi, K., Brownell, C., Werner, O. and Lavisza, Z. (2020). Reconfiguring STEAM through material enactments of mathematics and arts: A diffractive reading of young people's interdisciplinary math-artworks, in P. Burnard and L. Colucci-Gray (eds.), Why Science and Arts Creativities Matter: (Re-)configuring STEAM for future-making education (pp 171-200). Leiden, The Netherlands: Brill Publishing. https://doi.org/10.1163/9789004421585_012

Burns, K., Cahill-Jones, T., Carter, C. Stint, C. and Veart, L. (eds) (2021). STEAM Approaches Handbook. Birmingham: STEAM INC Project, Birmingham City University.

Catterall, L. G. (2017). A Brief History of STEM and STEAM from an Inadvertent Insider. The STE AM Journal, 3(1), Article 5. https://doi.org/10.5642/steam.20170301.05

Chappell, K. Hetherington, L., Ruck Keene, H., Wren, H., Alexopoulos, A., Ben-Horin, O., Nikolopoulos, K., Robberstad, J., Sotiriou, S. and Bogner, F. X. (2019). Dialogue and materiality/embodiment in science $\mid$ arts creative pedagogy: their role and manifestation. Thinking Skills and Creativity, 31, $296-322$. https://doi.org/10.1016/j.tsc.2018.12.008

Clark, B. and Button, C. (2011). Sustainability transdisciplinary education model: interface of arts, science, and community (STEM). International Journal of Sustainability in Higher Education, 12(1), 41-54. https://doi.org/10.1108/14676371111098294

Claville, M. O. F., Babu, S., Parker, B. C., Hill, E. V., Claville, E. W. and Penn-Marshall, M. (2019). NanoHU: A successful collaborative STEM model preparing African Americans for engagement in Nanoscience, Laying the foundation for transformative, institutional STEAM engagement. Broadening Participation in STEM (Diversity in Higher Education) 22, Emerald Publishing Limited, Bingley (pp 107-128). https://doi.org/10.1108/S1479364420190000022005

Colucci-Gray, L. (2020). Developing an ecological view through STEAM pedagogies in Science education, in L. Colucci-Gray and P. Burnard (eds.), Why Science and Art Creativities Matter: (Re-)Configuring STEAM for Futuremaking Education (Vol. 18). (Critical issues in the future of learning and teaching). Leiden, The Netherlands: Brill Publishing.

Colucci-Gray, L., Burnard, P., Cooke, C., Davies, R., Trowsdale, J. and Gray, D. (2017). Reviewing the potential and challenges of developing STE AM education through creative pedagogies for 21st learning: How can school curricula be broadened towards a more responsive, dynamic, and inclusive form of education? London, U.K.: British Educational Research Association.

Colucci-Gray, L., Burnard, P., Gray, D. and Cooke, C. (2019). A Critical Review of STEAM (Science, Technology, Engineering, Arts, and Mathematics), in P. Thomson (ed.), Oxford Research Encyclopedia of Education (Online chapter pp. 1-22). Oxford University Press. https://doi.org/10.1093/acrefore/9780190264093.013.398

Conradty, C. and Bogner F. X. (2018). From STEM to STEAM: How to Monitor Creativity. Creativity Research Journal, 30(3), 233-240. https:/ / doi.org/10.1080/10400419.2018.1488195

Costantino, T. (2018). STEAM by another name: Transdisciplinary practice in art and design education. Arts Education Policy Review, 119(2), 100-106. https:/ / doi.org/10.1080/10632913.2017.1292973

Cultural Learning Alliance. (2017). Why STEM can only take us so far. STEAM Briefing, 26 October 2017. London, U.K.: Cultural Learning Alliance and Nesta.

Danvers, J. (2003). Towards a Radical Pedagogy: Provisional Notes on Learning and Teaching in Art \& Design. International Journal of Art \& Design Education, 22(1), 47-57. https:/ / doi.org/10.1111/1468-5949.00338

De Fay, C. R. (2005). Art, enterprise, and collaboration: Richard Serra, Robert Irwin, James Turrell, and Claes Oldenburg at the Art and Technology Program of the Los Angeles County Museum of Art, 1967-1971. University of Michigan.

De la Garza, A. (2019) Internationalizing the curriculum for STEAM (STEM + Arts and Humanities): From intercultural competence to cultural humility. Journal of Studies of International Education, 25(2), $123-135$. https://doi.org/10.1177/1028315319888468

Drozd, A. L., Smith, R. L., Kostelec, D. J., Fallacaro Smith, M., Kelahan, G., Group, M., Drozd, E. M. and Bertrand, J. (2017). Rebuilding smart and diverse communities of interest through STEAM immersion learning, in 2017 IEEE Integrated STEM Conference (ISEC) (pp. 162-167). https://doi.org/10.1109/ISECon.2017.7910235

Gardner, H. (1993). Multiple Intelligences: The Theory in Practice. New York: Basic Books.

Girão, L. M., Stratford, A. and Hemment, D. (2018). Methodology for Integrating ICT and Art. Brussels: European Commission. 
Gooding-Brown, J. (2000). Conversations about Art: A disruptive model of interpretation. Studies in Art Education, 42(1), 36-50. https://doi.org/10.2307/1320751

Guyotte, K. W., Sochacka, N. W., Costantino, T. E., Kellam, N. N. and Walther, J. (2015). Collaborative creativity in STEAM: Narratives of art education students' experiences in transdisciplinary spaces. International Journal of Education \& the Arts, 16(15). https://doi.org/10.1007/978-981-13-2880-0_6

Guyotte, K. W., Sochacka, N. W., Costantino, T. E., Walther, J. and Kellam, N. N. (2014). Steam as Social Practice: Cultivating Creativity in Transdisciplinary Spaces. Art Education, 67(6), 12-19. https://doi.org/10.1080/00043125.2014.11519293

Huser, J. et al. (2020). STEAM and the Role of the Arts in STEM. New York: State Education Agency Directors of Arts Education.

Kim, Y. E., Morton, B. G, Gregorio, J., Rosen, D. S., Edouard, K. and Vallett, R. (2018). Enabling creative collaboration for all levels of learning. Proceedings of the National Academy of Sciences, 116(6), 1878-1885. https://doi.org/10.1073/pnas.1808678115

Malina, R. F., Strohecker, C. and LaFayette, C. (2015). Steps to an Ecology of Networked Knowledge and Innovation: Enabling New Forms of Collaboration among Sciences, Engineering, Arts, and Design. Cambridge, Massachusetts and London, England: The MIT Press.

Markussen, T. (2013). The disruptive aesthetics of design activism: Enacting design between art and politics. Design Issues, 29(1), 38-50. https://doi.org/10.1162/DESI_a_00195

Mejias, S., Thompson, N., Sedas, R. M., Rosin, M., Soep, E., Peppler, K., Roche, J., Wong, J., Hurley, M., Bell, P. and Bevan, B. (2021). The trouble with STEAM and why we use it anyway. Science Education, 105(2), 209-231. https://doi.org/10.1002/sce.21605

Partnership for 21st Century Skills (2007). Framework for 21st Century learning. http://static.battelleforkids.org/documents/p21/P21_Framework_Brief.pdf (Last accessed: 03/07/2021)

Pollock, I., Murray, J. and Yeager, B. (2017) Brain Jam - STEAM learning through Neuroscience-themed game development, in Proceedings of International Conference on Game Jams, Hackathons, and Game Creation Events. San Francisco, CA USA, February 2017 (7 pages). https://doi.org/10.1145/3055116.3055122

Robinson, K. (2011). Out of Our Minds: Learning to be Creative. Mankato, Minnesota: Capstone Publishing. https://doi.org/10.1002/9780857086549

Root-Bernstein, R. (2002). Aesthetic cognition. International Studies in the Pbilosophy of Science, 16(1), 61-77. https://doi.org/10.1080/02698590120118837

Schnugg, C. (2019). Creating ArtScience Collaboration: Bringing Value to Organizations. London: Palgrave MacMillan. https://doi.org/10.1007/978-3-030-04549-4

Schuitema, G. and Sintov, N. D. (2017) Should we quit our jobs? Challenges, barriers and recommendations for interdisciplinary energy research. Energy Policy, 101, 246-250. https://doi.org/10.1016/j.enpol.2016.11.043

Segarra, V. A., Natalizio, B., Falkenberg, C. V., Pulford, S. and Holmes, R. M. (2018). STEAM: Using the Arts to Train Well-Rounded and Creative Scientists. Journal of Microbiology \& Biology Education, 19(1), 1-7. https://doi.org/10.1128/jmbe.v19i1.1360

Thill, R., Strohecker, C., LaFayette, C. and Malina, R. (2016). Draft SEAD Network 5-Year Snapshort Update to 'Steps to an Ecology of Networked Knowledge and Innovation'. http://sead.viz.tamu.edu/pdf/SEAD_5YU.pdf (Last accessed: 29/06/2021).

Timotheou, S. and Ioannou, A. (2021). Collective creativity in STEAM Making activities. The Journal of Educational Research, 114(2), 130-138. https:/ / doi.org/10.1080/00220671.2021.1873721

Vaishnavi, V., Kuechler, W. and Petter, S. (eds) (2019). Design Science Research in Information Systems. (created 20/01/2004 and updated until 2015 by V. Vaishnavi and W. Kuechler; last updated by V. Vaishnavi and S. Petter, 30/06/2019). http://www.desrist.org/design-research-in-information-systems/.

Van Gansbeke, R. and Groenewould, L. (eds) (2020). S+T+Arts Collaboration Toolkit. STARTS Ecosystem ((H2020 CSA, GA No. 824950).

Wang, T. J. and Huang, K. H. (2018). Pedagogy, philosophy, and the question of creativity. Teaching in Higher Education, 23(2), 261-273. https://doi.org/10.1080/13562517.2017.1379479

Woodward, C. E. (1984). Art and elegance in the synthesis of organic compounds: Robert Burns Woodward, in D. B. Wallace and H. E. Gruber (eds.), Creative People at Work: Twelve cognitive case studies (pp. 227-253). New York: Oxford University Press. 